\title{
Human Papillomavirus Infections: Epidemiology, Clinical Aspects and Vaccines
}

\author{
Lynette Denny
}

Department of Obstetrics and Gynaecology, Gynaecology Oncology Unit, Groote Schuur Hospital and Institute of Infectious diseases and Molecular Medicine, University of Cape Town, South Africa

\begin{abstract}
Genital Human papillomavirus infections are the commonest sexually transmitted infections worldwide. The prevalence however in cytologically normal women varies from $1.4 \%$ in Spain to over $25 \%$ in some countries South of the Sahara. Globally about $10 \%$ of women are infected with HPV. The average duration of HPV infection is 4-20 months and the majority of infected individuals will clear the infection without any clinical consequences. Persistent infection with high-risk or oncogenic types of HPV is strongly associated with the development of preinvasive and invasive lesions of the ano-genital tract, including cancer of the cervix, anus, penis, vulva and vagina. HPV 16 is the most oncogenic type and is associated with an absolute risk of high grade cervical cancer precursors of $40 \%$ after 5 years of persistent infection. HPV infection of the epithelium is very effective at evading the host immune surveillance system due to the absence of a viraemic phase, using non-lytic replication and low expression of viral proteins until late stages of epithelial differentiation. Infection of the cervix with high-risk types of HPV is a necessary although insufficient cause of cervical cancer. Important co-factors include long term use of oral contraceptives, use of tobacco, co-infection with herpes simples, Chlamydia and HIV. This article discusses both secondary and primary prevention of cervical cancer, with particular emphasis on developing countries, where $80 \%$ of cervical cancer cases are found.
\end{abstract}

\section{INTRODUCTION}

Over a 150 different types of Human Papillomavirus (HPV) have been identified, of which about 40 are known to infect the anogenital tract. HPV's are DNA viruses that infect cutaneous and mucosal epithelia, manifesting as non-genital or genital warts, and preinvasive and invasive lesions. HPVs infecting the anogenital tract are divided into high-risk and low-risk types, based on their association with malignant or benign disease. HPV infection is associated with almost all cervical cancers, but also with other cancers of the anogenital tract including cancer of the vulva, vagina, anus, penis and some head and neck cancers.

Human papillomavirus particles consist of 8000 base-pair (bp) long circular DNA molecules wrapped into a protein shell composed of two molecules (L1 and L2). The viral genome has the coding for these two proteins and the six early proteins (E1, E2, E4 -E7), that are necessary for the replication of the viral DNA and for the assembly of the newly produced viral particles within infected cells. Both sets of genes are separated by an upstream regulatory region (URR) of about $1000 \mathrm{bp}$ that does not code for proteins but regulates gene expression, replication of the genome, and its packaging into viral particles [1].

HPV particles reach the basal layer of the epithelium, where they bind to and enter cells through microtrauma. Within the epithelium, the viral genome is replicated to a copy number of about 100 and maintained for varying

*Address correspondence to this author at the Department Obstetrics \& Gynaecology, Groote Schuur Hospital, H45, Old Main Building, Observatory 7925, Cape Town, South Africa; Tel: 2721404 4488; Fax: 27 21448 6921; E-mail: lynette.denny@uct.ac.za periods of time at this low copy number. The viral proteins E1 and E2 are essential for this basal DNA replication. Once the basal cells are pushed to the suprabasal compartment, they lose their ability to divide and initiate the terminal differentiation program. The critical molecules in the process of virus replication are the viral proteins E6 and E7, which interact with a variety of cellular proteins [1]. The best characterized interactions are with proteins $\mathrm{pRB}$ and $\mathrm{p} 53$. Binding of $\mathrm{E} 7$ to $\mathrm{pRB}$ activates the $\mathrm{E} 2 \mathrm{~F}$ transcription factor, which triggers the expression of proteins necessary for DNA replication. The E6 protein targets p53 for proteolytic degradation. As a consequence the dependence on cell cycle control is abolished and normal keratinocyte differentiation is retarded. As a result of virus infection, constant activity of the viral proteins E6 and E7 leads to increasing genomic instability, accumulation of oncogene mutations, further los of cell-growth control and ultimately malignant transformation.

\section{PREVALENCE AND INCIDENCE}

Genital HPV infection is the most common sexually transmitted infection in the world although detection of HPV types by polymerase chain reaction (PCR) assays varies greatly with age and by geography. Clifford et al. [2] randomly selected women from 11 countries for HPV DNA testing using GP5+/6+ PCR analysis. Women aged 15-74 years who did not have cytological abnormalities were included $(\mathrm{n}=15613)$. They found that age standardized prevalence varied nearly 20 times between different populations: from $1.4 \%$ in Spain, to $25.6 \%$ in Nigeria. Overall, age standardized HPV prevalence was five times higher in sub-Saharan Africa than in Europe with intermediate prevalence in South America and Asia. In terms of types, HPV type 16 was the commonest type in all regions 
except in sub-Saharan Africa, where HPV type 35 was equally as common.

Sanjose et al. [3] performed a meta-analysis of 157879 women with normal cytology (from 78 studies) who underwent HPV DNA testing. The prevalence of HPV was estimated to be $10.4 \%$ (95\% CI:10.2-10.7) globally and the prevalence was higher in less developed countries overall (15.5\%) compared to more developed countries (10.6\%).. Corresponding prevalence estimates for Africa were $22.1 \%$, Central America and Mexico 20.4\%, Northern America $11.3 \%$, Europe $8.1 \%$ and Asia $8.0 \%$. Age specific prevalence was possible to estimate from 44 studies, and HPV prevalence was shown to be highest in women younger than 34 years, with a decrease in the 35-44 year group. There was as second peak from age 45-54 years in all regions except Asia [2].

In this same analysis, 48 studies provided HPV-type specific prevalence data in women with normal cytology [3]. The five most common types of HPV were HPV 16 (2.5\%), HPV 18 (0.9\%), HPV $31(0.7 \%)$, HPV 58 (0.6\%) and HPV $52(0.6 \%)$. The authors estimated that the overall burden of HPV infection from the age-specific adjusted prevalence in cytologically normal women to be 291 million women infected with HPV of whom $23.3 \%$ were estimated to be infected with HPV 16 and 8.5\% with HPV 18.

HPV infection is also very common in men although it has not been studied as extensively in men as in women. Partridge et al. [4] recruited 240 heterosexually active male university students age 18 and 20 years, from whom genital samples were performed at 4 monthly intervals over 24 months. At 24 months, the cumulative incidence of new infection of any genital HPV type was $62.4 \%$. Acquisition rates did not differ by genital site (i.e. glans, penile shaft, or scrotum) of initial detection. This cumulative incidence rate is nearly twice that reported in a similar group of female students. Ho et al. [5] reported a $43 \%$ cumulative 36 month incidence of HPV infection among women who were HPV negative at baseline and with a mean age of 20 years.

Winer et al. [6] followed 603 female university students, aged 18 to 20 years, at 4 month intervals between 1990 and 2000. Nearly $20 \%$ of women had HPV DNA detected at the first visit. Of the 444 women who were HPV negative at baseline and who engaged in penetrative sex with a male partner, the cumulative 24 month incidence of HPV in women who were sexually active at baseline was $38.8 \%$ and among virgins who initiated sexual activity during this period, it was $38.9 \%$. HPV type 16 was the most common type detected, with a 24 month incidence of $10.4 \%$. The similar incidence of infection in virgins who became sexually active and women who were already sexually active, suggests that HPV acquisition is independent of prior sexual experience. An increased risk of incident HPV infection is more strongly associated with sex with a new partner than sex with ongoing partners. In addition, report of a new partner was associated most strongly with incident HPV infection when the new partner was acquired 5-8 months before assessment of HPV status.

The same group reported on a group of 130 women who reported their first intercourse with a male partner within 3 months of enrollment [7]. The study was designed to quantify the cumulative incidence of first HPV infection associated with a first sex partner. This study reported that just under $30 \%$ of these women tested positive for HPV DNA within one year of their first intercourse with a first male sex partner and by 3 years, nearly $50 \%$ tested positive. The risk of acquiring HPV infection from a first male partner was strongly associated with the sexual history of the male partner.

\section{DURATION, PERSISTENCE AND CLEARANCE OF HPV INFECTION}

Across a number of studies, the average duration of individual episodes of HPV infection last from 4-20 months $[8,9]$. Most studies however indicate that less than half of infected women will still be HPV positive at the end of 12 months. High risk type infections tend to last longer than low risk infections, particularly HPV 16 infections which tend to last the longest.

In general, most HPV infections tend to clear with time, as do warts anywhere on the body. However, viral clearance is not often followed by reappearance of the same HPV genotype. When the same type reappears it is unclear whether these represent new infections or resurgence of an ill-defined latent state. The issue of latency remains to be convincingly resolved, but the increased prevalence and persistence of HPV infection in HIV infected individuals, supports the notion of latency [10]. Reactivation of HPV infection has been observed in immunosuppressed women, but its frequency in immunocompetent women remains undetermined. Other evidence of latency comes from populations in which prevalence of HPV rises secondarily among older women, however this could also be explained by sexual behavior or cohort effects.

It is clear that the persistent infection of high-risk types of HPV is associated with the development of intra-epithelial or precancerous lesions. The modal time between HPV infection and CIN 3 or HSIL, has been calculated to be 7-15 years, with infection occurring in late teens or early twenties and CIN 3 diagnosis in late twenties or early thirties [11]. It is now believed that HPV type affects both the absolute risk of viral persistence and or progression to precancer given viral persistence. HPV 16 is strongly oncogenic with an absolute risk of CIN 3 approaching $40 \%$ at 5 years of persistence. Viral load is also important, with low viral loads having a low risk of subsequent precancer or cancer, however from a clinical point of view, the prognostic significance of high viral loads is not clear [12]. Some of the highest viral loads are associated with resolving CIN 1 lesions, producing large amounts of virus similar to that found in genital warts. By contrast, cervical cancers do not produce large amounts of intact virus, and this is most likely linked to the disruption of the HPV virion that precedes genomic integration.

There are many unique features of HPV infection and the host immune response that influences the natural history of HPV infection. Much of what is known about the mechanisms of HPV infection and the host immune response has been derived from animal and in-vitro models. Recent studies indicate that HPVs require at least a microabrasion of the cell lining of the cervix or vagina to allow infection of basal cells of the epithelium. On infection of a basal cell and 
the establishment of the autonomously replicating viral genome in the cell nucleus, the life-cycle of HPV progresses synergistically with the differentiation of the epithelial cell [13]. By infecting first the basal layer of the cervical epithelium and having no viraemic phase, HPVs are isolated from circulating immune cells as infection becomes established. Their non-lytic replication limits innate immune responses that would normally occur in response to cell death and viral proteins are not expressed at high levels until later stages of epithelial differention. Together, the limited innate immune response, the low levels of viral gene expression in the basal epithelium and the lack of cytopathic effects generally result in a delayed adaptive immune response to initial HPV infection, thus favouring the establishment of viral infection [13].

\section{HPV INFECTION IS A SEXUALLY TRANSMITTED DISEASE}

While non-sexual means of transmission are possible, most studies have clearly shown that genital HPV is transmitted through sexual contact. Epidemiological studies have consistently shown that the most important determinants of HPV infection in women are the number of sexual partners, the age of initiation of sexual activity, and the sexual behaviour of the male partner [14,15]. Kjaer et al. [14] studied a cohort of 100 virgins and 105 monogamous women and showed that all the women who remained virgins throughout the study period, tested negative for both HPV DNA and serum HPV-16 antibodies at enrollment and each visit thereafter. The most important determinant of HPV DNA acquisition in that study was the number of sexual partners between enrollment and subsequent visits.

\section{OTHER ROUTES OF TRANSMISSION}

The evidence for nonsexual transmission of genital types of HPV indicate that genital HPV infection, including genital warts may occur in sexually naive populations such as infants, children, virgin adolescents and adults. Secondly, there is some evidence of horizontal transmission and vertical and perinatal transmission of HPV from mother to child. Moreover, high risk genital types of HPV have been detected in non-genital epithelia such as the conjunctiva, mouth and oro-pharynx and cancers have been associated with HPV infection at these sites.

Juvenile Onset Recurrent Laryngeal Papillomatosis (JORLP) is a documented rare outcome of infection with HPV types 6 and 11 due to perinatal transmission of HPV [16]. One study estimated that laryngeal papillomatosis develops in 7 out every 1000 infants born to mothers with genital warts during pregnancy, and the hypothesis is that transmission occurs due to exposure to the virus in the birth canal [17]. In addition, some studies have shown evidence of intra-uterine infection, with HPV detected in amniotic fluid, suggesting that ceasarian section has little role to play in the prevention of perinatal transmission of HPV [18]. While perinatal transmission certainly occurs, it appears that the only serious consequence of this transmission is recurrent laryngeal papillomatosis, which is fortunately extremely rare. While HPV is commonly detected in pregnant women, detection of HPV in newborns is rare and is not associated with persistent infection.

\section{HUMAN PAPILLOMAVIRUS INFECTION AND CERVICAL CANCER}

Cancer of the cervix is the commonest cancer found among women in the developing world, where more than $80 \%$ of all cases are diagnosed. In 2002, there were an estimated 493000 new cases and 274000 deaths from cervical cancer [19]. The highest incidence rates of cervical cancer are observed in sub-Saharan Africa, Melanesia, Latin America and the Caribbean, South Central Asia, and South East Asia [19].

There is now a considerable body of epidemiological, clinical and molecular evidence that persistent infection of the cervix with high-risk types of HPV is necessary for the development of cervical cancer. High-risk types of HPV are identified in nearly all carcinomas of the cervix and the relative risk of cervical cancer associated with infection with high-risk types of HPV is higher than the risk of lung cancer associated with smoking [20].

Munoz et al. [21] pooled data from 11 case-control studies involving 1918 women with histologically confirmed squamous cell carcinoma of the cervix and 1928 control women. The pooled odds ratio for cervical cancer associated with the presence of any HPV was 158.2 (95\% CI: 113.4220.6). On the basis of the pooled data, fifteen HPV types were classified as high-risk types $(16,18,31,33,39,45,51$, $52,56,58,59,68,73$, and 82) and are considered carcinogenic; 3 were classified as probably high-risk types $(26,53$ and 66$)$; and 12 were classified as low-risk types $(6,11,40,42,43,44,54,61,70,72,81$ and CP6108).

In a meta-analysis of HPV types found in invasive cervical cancers worldwide [22] data on a total of 14595 cases of invasive cancer (which included squamous cell carcinomas, adenocarcinomas and adeno-squamous carcinomas) confirmed the high prevalence of HPV in cervical cancers in different regions of the world, with HPV $16(52-58 \%)$ and $18(13-22 \%)$ being the commonest. However, more than 16 other types of HPV were also associated with cervical cancer, of which types $31,33,35$, 45, 52 and 58 were the most prevalent. Further, HPV type 16 was more prevalent in squamous carcinomas and HPV type 18 more prevalent in adenocarcinomas of the cervix. Overall, HPV prevalence differed little between geographical regions (86-94\%) but was low compared to the almost $100 \%$ prevalence in studies that have used the most sensitive methods of detection for HPV. Overall HPV prevalence in HSIL (7 094 cases of HSIL underwent HPV DNA typing) was $85 \%$, ranging from $78 \%$ in Asia, to $88 \%$ in Europe. Combined HPV 16/18 prevalence in all HSIL cases was $52 \%$, with HPV 16 being the predominant type of HPV from all continents studied, varying from $34 \%$ in Asia to $52 \%$ in Europe

There is good evidence that HPV infection precedes the development of cervical cancer by a number of decades and that persistent infection with HPV is necessary for the development of and progression of pre-cancerous lesions of the cervix, either to higher grades of pre-cancerous disease or to cancer [23-25]. However important HPV infection is for the development of cervical cancer, it is clear that there are other endogenous and exogenous factors necessary for the progression from HPV infection to cervical cancer and it 
precursors. Co-factors that have been investigated and found to be associated with cervical cancer and its precursors, include long-term use of oral contraceptives, tobacco smoking, co-infection with other sexually transmitted agents such as herpes simplex 2, Chlamydia trachomatis and HIV.

The Collaborative Group on Epidemiological Studies of Cervical Cancer reanalysed data from 24 epidemiological studies worldwide to investigate the association between cervical cancer and contraceptive use [26]. Individual data for 16573 women with cervical cancer and 35509 women without cervical cancer were reanalysed. They found that among current users of oral contraceptives, the risk of invasive cancer increased with duration of use (relative risk for 5 or more years use $v s$ never use was 1.90 (95\% CI: 1.69 2.13). The risk declined after use ceased and by 10 or more years had returned to that of never users. The effects of smoking have been studied in a number of case-control studies, and they show a moderate and statistically significant association with cervical cancer, even after adjusting for the strong effects of HPV [27, 28].

\section{PREVENTION OF CERVICAL CANCER: ISSUES IN DEVELOPING COUNTRIES}

The unique natural history of cervical cancer lends itself to both primary and secondary interventions to prevent the disease. Historically, secondary prevention methods using cytology to detect cervical cancer precursors, followed by colposcopy and removal of precursor lesions, have been associated with a dramatic reduction in cervical cancer in those countries that have successfully implemented mass, cytology-based screening programmes. The majority of successful programmes are found in developed countries, whereas there are few if any screening programmes in developing countries, where the greatest burden of cervical cancer is found.

The challenges posed by cytology-based screening programs in resource restricted environments, have prompted the search for alternative, technologically more appropriate and more affordable screening methods. Visual inspection with acetic acid, known as VIA, involves examination of the cervix after the application of 3-5\% acetic acid, using the naked eye aided by a bright light source. The test characteristics of VIA have been evaluated in a number of cross-sectional studies in developing countries, summarised by Sankaranarayanan et al. [29] and Denny [30]. These studies have included nearly 150000 women and have reported sensitivities of VIA for high-grade intraepithelial lesions which have ranged from 49-96\% with specificities between 49 and $98 \%$.

Denny et al. performed a randomized controlled trial of 6555 women aged 35-65 in Cape Town, South Africa [31]. This trial evaluated three 'screen and treat' strategies: 1] Screening with VIA followed by crytotherapy if positive; 2] Screening with HPV DNA testing using Hybrid Capture II followed by cryotherapy if positive; 3] control group had delayed treatment for 6 months regardless of the result of the screening tests (VIA and HPV DNA testing). The prevalence of high grade cervical cancer precursors (defined histologically) was significantly lower in the two 'screen and treat' groups 12 months post randomisation compared to the delayed evaluation group. HPV DNA testing followed by cryotherapy was twice as effective in reducing high-grade lesions compared to VIA followed by cryotherapy.

Recently Sanakaranarayanan et al. have reported on a cluster-randomised trial performed in 114 clusters in Dindigul district, India [32]. Fifty seven clusters or areas were randomized to one round of VIA by trained nurses followed by treatment with cryotherapy if positive and 57 to a control group. This study was the first to report on a reduction in cervical cancer incidence in the intervention $v s$ the control group (all other VIA studies have used intraepithelial lesions as the outcome). This study showed a reduction of $25 \%$ in cervical cancer incidence and a $35 \%$ reduction in mortality compared to the control group in this trial located in South India.

In another study [33], the same group reported on a cluster randomised trial involving 52 clusters of villages, with a total of 131746 healthy women between the ages of 30 and 59 years. The groups were randomised to undergo screening by HPV testing, cytologic testing, VIA or standard of care (no screening). Women with positive screening tests were referred for colposcopy and biopsy and for treatment if lesions were detected. The hazard ratio for the incidence of advanced cancer and death in the HPV testing groups were 0.47 (95\% CI:0.32-0.69) and 0.52 (95\% CI: 0.33-0.83) respectively, as compared with the control group. There were no significant reductions in the numbers of advanced cancers or deaths observed in the cytologic-testing and the VIA group compared to the control group. These data represent 8 years of follow-up and is the second study to use cancer diagnosis as an endpoint. In this study, a single round of HPV testing was associated with a significant reduction in the numbers of advanced cervical cancers and deaths from cervical cancer and neither VIA nor cytology were, compared to the control group. The reason for the evidence of reduction of cancer in the first but not the second trial is not clear, but may be due to the higher incidence of treatment in the former trial.

VIA lends itself to 'screen and treat' strategies and has many advantages in low resource settings, particularly the option of a 'one-stop' visit to the clinic. Disadvantages of VIA include its relatively low specificity and PPV, resulting in considerable over-treatment. In addition, it is very difficult to provide reliable quality control of VIA which may lead to very different performance characteristics in different settings. However, despite its shortcomings, no other current screening option is economically viable in many poor countries. Currently the World Health Organisation is funding 'VIA and treat' roll-out studies in six African countries and preliminary reports are very positive, indicating that 'something is better than nothing'. VIA has enabled severely resource-restricted countries to establish some form of screening infrastructure for older women. While the impact on cervical cancer prevention is likely to be modest to small, creating an infrastructure for the health care of older women is a very good start.

Goldie et al. [34] investigated the cost-effectiveness of a variety of cervical cancer screening strategies in India, Kenya, Peru, South African and Thailand. They reported that screening women once in their lifetime, at the age of 35 years, with a one- or two-visit strategy using VIA, reduced the lifetime risk of cervical cancer by approximately $25-36 \%$ 
and cost less than 500 international dollars per year of life saved. Relative cancer risk declined by an additional $40 \%$ with two screenings at ages 35 and 40 years. The study concluded that VIA (followed by immediate treatment of positive cases, on site) or two clinical visits (followed by treatment without prior colposcopic evaluation of positive cases) is one of the most cost-effective alternatives to conventional three visit screening strategies using cytology, followed by colposcopy and biopsy of positive cases and then treatment of high grade precursors.

\section{HPV DNA TESTING}

As already mentioned, infection of the cervix with highrisk types of HPV is necessary for the development of cervical cancer and high-risk types of HPV are detectable in nearly all cervical cancers. In the 1990s an assumption was made that detecting the causative agent of cervical cancer would have acceptable diagnostic performance, and being an objective test, would overcome the subjective nature of cytology. HPV DNA testing has been studied in a variety of clinical settings: 1] Triage of borderline or minor cytological abnormalities; 2] Primary screening test; 3 ] In combination with other screening tests e.g. cytology or VIA and 4] for follow up post treatment for cervical cancer precursors.

It is beyond the scope of this article to review the extensive literature on HPV DNA testing and screening. There are a number of comprehensive reviews to which the reader is referred [35-38]. To summarise, HPV DNA testing whether by Hybrid Capture (Digene Diagnostics, Gaithersburg, MD, USA) which is FDA approved or PCRbased assays (no commercially available or FDA approved kits available to date), in both cross-sectional and longitudinal studies has been shown to:

- Consistently and in different settings to have higher sensitivity than cytology for the detection of high grade precursors (in most studies HPV testing is $20 \%$ more sensitive than cytology)

- Consistently and in different clinical settings to have a lower specificity and PPV compared to cytology, with a false positive rate of approximately $5 \%$

- $\quad$ NPV is virtually $100 \%$, and women negative for highrisk HPV are at very low risk for cervical cancer

- $\quad$ Significantly higher sensitivity than cytology for detection of persistence/recurrence of SIL/CIN post treatment

- More reliable, reproducible and objective than cytology

The low specificity of HPV DNA testing is of concern, particularly in large scale 'screen and treat' programs, a high false positive rate would lead to significant over-treatment of women. However, women who have a positive test for highrisk HPV are at considerable risk of developing SIL or CIN in the future and warrant more intensive surveillance. Castle et al. [39] followed over 2000 women who had negative cytology but a positive high-risk Hybrid Capture (HC II) HPV DNA test for a 57 month period and found that $15 \%$ of these women developed an abnormal Pap smear in this nearly 5 year period. Similarly, Koutsky et al. [40] and showed that $28 \%$ of women who were high-risk HPV positive with negative cytology developed high-grade SIL over a 25 month period compared to $3 \%$ of HPV negative women. Rozendal et al. [41] reported that women with negative cytology but a positive HPV test had a 116-fold increase risk of developing CIN 3 compared to HPV negative women over a 40 month follow-up period.

HPV DNA testing offers some advantages over cytology, but is currently far too expensive for developing countries and the laboratory infrastructure too sophisticated. In addition, HPV DNA testing, while more efficient and able to process many more samples per day compared to cytology, is still a laboratory based test with all the disadvantages this holds for countries with resource-restricted health care infrastructure. Qiao et al. [42] recently published a crosssectional study of a new test (careHPV, Qiagen, Gaithersburg, MD, USA) which has been developed to detect 14 high-risk types of HPV in about 2.5 hours and can be performed on site. The study showed the sensitivity and specificity for HSIL of careHPV to be $90 \%$ and $84.2 \%$ respectively compared to 97 and $85.6 \%$ for Hybrid Capture 11 . These results are very encouraging and may enable 'screen and treat' protocols to be implemented in low resource settings at an affordable cost.

Another important consideration with regards to HPV DNA testing, is the prevalence of infection of HIV, which is very high in many developing countries. Of the approximately 40 million HIV infected individuals in the world at the end of 2006, 25 million were resident in subSaharan Africa, and over $50 \%$ of those infected were women [www.unaids.org]. The expected increase in women diagnosed with cervical cancer in Africa during the HIV pandemic has not been convincingly observed, most likely due to most at-risk women dying from other opportunistic infections prior to developing cervical cancer or its precursors. However, in the era of anti-retroviral medication, this scenario may change. Studies have consistently shown higher prevalence of HPV infection, persistent infection with HPV, infection with multiple types of HPV and higher prevalence of cervical cancer precursors in HIV infected women [43-46]. The high prevalence of HPV-associated disease in these patients will most likely render HPV DNA testing far too non-specific for it to have a meaningful role in screening. In fact, to be provocative, due to the very high prevalence of HPV infection in HIV infected women, there have been suggestions that all HIV positive women undergo prophylactic ablation of the transformation zone of the cervix. This is however an untested approach.

The Rwandan Women's Interassociation Study and Assessment (RWISA) is an observational prospective cohort study of 710 HIV positive women and 226 HIV negative Rwandan women, enrolled into the study in 2005 . The prevalence of HPV was significantly higher in the HIV positive group and adjusted for age $(25-34$ years $75 \%$ vs $29 \%$; $35-44$ years 64 vs 7\%; $45-54$ years $57 \%$ vs $13 \%$ and over 55 years $38 \%$ vs $0 \%$ ) [47]. In addition $46 \%$ of HIV positive women had high-risk types of HPV and 35\% were infected with multiple types and in turn, this was associated with higher risk of abnormal cytological findings. Denny et al. [46] found that $68 \%$ of their cohort of HIV positive women were infected with high-risk types of HPV, and 94\% 
of these infections persisted over a 36 month period, with only $6 \%$ clearing infections.

\section{PRIMARY PREVENTION OF CERVICAL CANCER: HPV VACCINES}

The development of vaccines against certain types of HPV has been a major breakthrough in the options available for the prevention of cervical cancer. Monovalent (against HPV 16), bivalent (against HPV 16, 18; Cervarix, GlaxoSmithKline Biologicals, Rixensart, Belgium) and quadrivalent (against HPV 6, 11, 16, 18; Gardasil, Merck and Co., Inc, West Point, Pennsylvania, USA) vaccines have been tested in randomised placebo-controlled trials and shown to be safe, immunogenic and highly efficacious up to 6.5 years after vaccination. The vaccines use HPV typespecific L1 proteins that self-assemble into virus-like particles (VLPs). In the bivalent vaccine, the $\mathrm{L} 1$ protein of each type is expressed via a recombinant baculovirus vector. The vaccine consists of purified L1 VLPs of HPV types

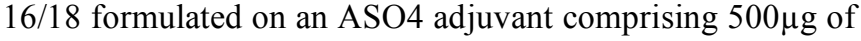
aluminium hydroxide and $50 \mu \mathrm{g}$ of 3-dacylated monophosphoryl Lipid A. The vaccine is delivered by intramuscular injection at 0,1 and 6 months.

In the quadrivalent vaccine, the L1 protein for each HPV VLP type is expressed via a recombinant Saccharomyces pombe vector and the vaccine consists of purified L1 VLPs of HPV types 6/11/16/18 formulated on a proprietary alum adjuvant. The vaccine is also given via intramuscular injection, at 0,2 and 6 months.

Both vaccines work by inducing neutralising serum antibodies (IgG). Studies consistently show that L1 VLPs induce high levels of serum neutralising $\mathrm{IgG}$, that is presumed to transudate across the cervical epithelium in high enough concentration to bind to virus particles and prevent infection.

There is good evidence provided by randomised placebocontrolled trials that these vaccines prevent both persistent infection with the types included in the vaccines, as well as pre-invasive lesions of the anogenital tract associated with the types present in the vaccines [47-53].

Both vaccines appear to offer protection against types 16 and 18 , which are estimated to cause over $70 \%$ of cervical cancers worldwide, and a slightly lower fraction of cervical cancer precursors. There are some data that the immune response to vaccination against types 16 and 18 provides some cross-protection against types 45 and 31 , both important in the aetiology of cervical cancer, thus increasing the projected protection from vaccination to $75-80 \%$.

However, both vaccines are prophylactic and should be administered to individuals prior to infection. As mentioned above, HPV is most commonly transmitted through sexual activity and is known to be the commonest sexually transmitted infection in the world. Thus the vaccine should ideally be administered to girls (and possibly boys) prior to the onset of sexual activity, which varies considerably from country to country and in different cultures. Vaccination of girls aged 9-12 years of age with high coverage is most likely going to be the most clinically effective and costeffective strategy for cervical cancer prevention.
From a developing country point of view introducing the HPV vaccine into public health poses many challenges. The most obvious is cost, and the present price of both vaccines is unaffordable. However, cost is only one aspect. Firstly, no developing countries have established pubescent/adolescent health platforms or school health systems from which to vaccinate young girls (and possibly boys). This infrastructure will have to be created de novo and for this to happen, a great deal of political will need to be generated. Unfortunately, no studies have included infants, so neither vaccine will be approved for integration into the Extended Programme for Immunisation (EPI) that has been successfully introduced into many developing countries, with high coverage. EPI is believed to save 3 million young lives per year.

Besides the need to create a new infrastructure, both vaccines require a cold chain, thus a reliable source of electricity, which is notoriously difficult in many developing countries, particularly in Africa. The need for 3 injections and therefore follow-up poses its own challenges, as does the necessity for intra-muscular injection (skills, medical waste disposal). Furthermore, one is injecting a young girl to prevent a disease that will only manifest after 30 years or more. Developing a national strategy will require those familiar with vaccination (paediatricians, public health officials) to communicate with those who work in the adult oncology field (traditionally two worlds that never intersect). However, developing a pubescent or adolescent health platform may be highly desirable. Such a platform would be a unique opportunity to offer parallel services to young people e.g. booster vaccination against hepatitis B and tetanus, possibly anti-HIV vaccination in the future, antihelminthic medication, nutritional assessment, and education about drug, tobacco and alcohol use, pregnancy prevention and sexuality in general.

Whether or not countries introduce the vaccine into the public health sector will be determined by 1] the burden of HPV associated disease in a particular country 2] being able to convince politicians and health officials (particularly those who work with children and vaccination) that it is worthwhile to invest in vaccinating children to prevent a disease of adulthood, 3] the creation of the appropriate infrastructure for the administration of the vaccine and finally 4] the cost. Clearly, implementing anti-HPV vaccination involves a great deal more than getting the needle in the arm!

\section{DISEASE RELATED TO INFECTION WITH HPV 6/11}

Genital warts or condylomata accuminata are caused by HPV types 6 and 11, although about $20-50 \%$ of lesions also contain co-infections with high-risk HPV types [54]. While a benign condition, genital warts cause considerable psychological and sexual morbidity with substantial associated health care costs. Genital warts are highly infectious with a transmission rate of $65 \%$ within sexual partnerships and an incubation period of between 3 weeks and 8 months [54]. In some instances genital warts become huge, particularly in pregnant women or immunosuppressed individuals. Treatment using a variety of modalities is associated with a significant recurrence rate, ranging from $25-70 \%$. The occurrence of genital warts is strongly 
associated with sexual behaviour, more weakly associated with cigarette use and an inconsistent association with oral contraceptive usage. Consistent use of condoms decreases the risk of genital warts by $60-70 \%$ [55].

HPV-6 and 11 are frequently associated with LSIL. A recent meta-analysis of 55 studies reported HPV 6 to be present in $8.1 \%$ of HPV-positive LSIL cases and HPV 11 in $3.2 \%$ of cases, although HPV 16 was in fact the most prevalent HPV type in a variety of geographic regions [56]

\section{CONCLUSION}

The burden of disease associated with HPV infection is considerable, affecting all regions of the world and adding considerable costs to health. The era of HPV vaccination is a major breakthrough although it will be many years before there is adequate coverage of the world's population and for the impact to be quantifiable.

\section{REFERENCES}

[1] Munoz N, Castellsague X, Berrington de Gonzalez A, Gissman L. HPV in the etiology of human cancer. Vaccine 2006; 24(Suppl 3): S3/1-10.

[2] Clifford GM, Galios S, Herrero R, et al. Worldwide distribution of human papillomavirus types in cytologically normal women in the International Agency for Research on Cancer HPV prevalence surveys: a pooled analysis. Lancet 2005; 366: 991-8.

[3] de Sanjose S, Diaz M, Castellsague X, et al. World wide prevalence and genotype distribution of cervical human papillomavirus DNA in women with normal cytology: a metaanalysis. Lancet Infect Dis 2007; 7: 453-9.

[4] Partridge JM, Hughes JP, Feng Q, et al. Genital human papillomavirus infection in men: incidence and risk factors in a cohort of university students. J Infect Dis 2007; 196: 1128-36.

[5] Ho GY, Beirman R, Beardsley L, Chang CJ, Burk RD. Natural history of cervicovaginal papillomavirus infection in young women. N Engl J Med 1998; 338: 423 -8.

[6] Winer RL, Lee SK, Hughes JP, Adam DE, Kiviat NB, Koutsky L. Genital human papillomavirus infection: incidence and risk factors in a cohort of female university students. Am J Epidemiol 2003; 157: 218-26.

[7] Winer RL, Feng Q, Hughes JP, O'Reilly S, Kiviat NB, Koutsky LA. Risk of female human papillomavirus acquisition associated with first male sex partner. J Inf Dis 2008; 197: 279-82.

[8] Richardson H, Kelsall G, Tellier P, et al. The natural history of type-specific human papillomavirus infections in female university students. Cancer Epidemiol Biomarkers Prev 2003; 12: 485-90.

[9] Giuliano AR, Harris R, Sedjo RL, et al. Incidence, prevalence and clearance of type-specific human papillomavirus infections: The Young Women's Health Study. J Infect Dis 2002; 186: 462-9.

[10] Strickler HD, Burk RD, Fazzari M, et al. Natural history and possible reactivation of human papillomavirus in human immunodeficiency virus-positive women. J Natl Cancer Inst 2005; 97: 577-86.

[11] Bosch FX, de Sanjose S. Human papillomavirus and cervical cancer burden and assessment of causality. J Natl Cancer Inst Monogr 2003; 31: 3-13.

[12] Lorincz AT, Castle PE, Sherman ME, et al. Viral load of human papillomavirus and risk of CIN 3 or cervical cancer. Lancet 2002; 360: 228-9.

[13] Einstein M, Schiller J, Viscidi R, et al. Clinician's guide to human papillomavirus immunology: knowns and unknowns. Lancet Infect Dis 2009; 9: 347-56.

[14] Kjaer SK, Chackerian B, van den Brule AJC, et al. High-risk human papillomavirus is sexually transmitted: evidence from a follow-up study of virgins starting sexual activity (intercourse). Cancer Epidemiol Biomarkers Prev 2001; 10: 101-6.

[15] Castellsague X, Ghaffaria A, Daniel RW, Bosch FX, Munoz N, Shah KV. Prevalence of penile human papillomavirus DNA in husbands of women with and without cervical neoplasia: a study in Spain and Colombia. J Infect Dis 1997; 176: 353- 61.
[16] Cason J. Perinatal acquisition of cervical cancer associated papillomaviruses. Br J Obstet Gynaecol 1996; 103: 853-8.

[17] Silverberg MJ, Thorsen P, Lindeberg H, Grant LA, Shah KV. Condyloma in pregnancy is strongly predictive of juvenile-onset recurrent respiratory papillomatosis. Obstet Gynecol 2003; 101: 645-52.

[18] Armbruster-Moraes E, Ioshimoto LM, Leao E, Zugaib M. Presence of human papillomavirus DNA in amniotic fluids of pregnant women with cervical lesions. Gynecol Oncol 1994; 54: 152-8.

[19] Ferlay J, Bray F, Pisani P, Parkin DM. GLOBOCAN 2002 cancer incidence: mortality and prevalence worldwide. IARC CancerBase No. 5 version 2.0 Lyon: IARC Press 2004

[20] Walboomers JM, Jacobs MV, Manos MM, et al. Human papillomavirus is a necessary cause of invasive cervical cancer world wide. J Pathol 1999; 189: 12-9.

[21] Munoz N, Bosch FX, de Sanjose S, et al. Epidemiologic classification of human papillomavirus types associated with cervical cancer. N Eng J Med 2003; 348: 518-27.

[22] Smith JS, Lindsay L, Hoots B, et al. Human papillomavirus type distribution in invasive cervical cancer and high-grade cervical lesions: a meta-analysis update. Int J Cancer 2007: 121: 621-32.

[23] Liaw KL, Glass AG, Manos MM, et al. Detection of human papillomavirus DNA in cytologically normal women and subsequent cervical squamous intraepithelial lesions. J Natl Cancer Inst 1999; 91: 954-60.

[24] Nobbenhuis MA, Walboomers JM, Helmerhorst TJ, et al. Relation of human papillomavirus status to cervical lesions and consequences for cervical cancer screening: a prospective study. Lancet 1999; 354: 20-5.

[25] Yitalo N, Josefsson A, Melbye M, et al. A prospective study showing long-term infection with human papillomavirus 16 before the development of cervical carcinoma in situ. Cancer Res 2000; 60: 6027-32.

[26] International Collaboration of Epidemiological Studies of Cervical Cancer. Cervical cancer and hormonal contraceptives: collaborative reanalysis of individual data for 16573 women with cervical cancer and 35509 women without cervical cancer from 24 epidemiological studies. Lancet 2007; 379: 1609 -21.

[27] Ho GY, Kadish AS, Burk RD, et al. HPV 16 and cigarette smoking as risk factors for high-grade cervical intra-epithelial noeoplasia. Int J Cancer 1998; 78: 281-5.

[28] Morena V, Munoz N, Bosch FX, et al. Risk factors for progression of cervical intraepithelial neoplasm grade III to invasive cervical cancer. Cancer Epidemiol Biomarkers Prev 1995; 4: 459- 67.

[29] Sankaranarayanan R, Gaffikin L, Jacob M, Sellors J, Robles S. A critical assessment of screening methods for cervical neoplasia. Int J Gynaecol Obstet 2005; 89 (Suppl 2): S4-S12.

[30] Denny L. The prevention of cervical cancer in developing countries. BJOG 2005; 112: 1204-12.

[31] Denny L, Kuhn L, De Souza M, Pollack AE, Dupree W, Wright TC, Jr. Screen-and-treat approaches for cervical cancer prevention in low-resource settings: a randomized controlled trial. JAMA 2005; 294: 2173-81

[32] Sankaranarayanan R, Esmy PO, Rajkumar R, et al. Effect of visual screening on cervical cancer incidence and mortality in Tamil Nadu, India: a cluster-randomised trial. Lancet 2007; 370: 398406.

[33] Sankaranarayanan R, Nene B, Shastri S, et al. HPV screening for cervical cancer in rural India. N Engl J Med 2009; 360: 1385-94.

[34] Goldie SJ, Gaffikin L, Goldhaber-Fiebert JD, et al. Costeffectiveness of cervical cancer screening in five developing countries. N Engl J Med 2005; 353: 2158- 68 .

[35] Arbyn M, Sasieni P, Meijer CJLM, Duval C, Koliopoulos G, Dillner J. Clinical applications of HPV testing: a summary of metaanalyses. Vaccine 2006; 24(Suppl 3): S3/78-89.

[36] Cuzick J, Mayrand MH, Ronco G, Snijders P, Wardle J. New dimensions in cervical cancer screening. Vaccine 2006; 24(Suppl 3): S3/90- 97.

[37] Franco EL. Primary screening fo cervical cancer with human papillomavirus tests. J Natl Cancer Inst Monogr 2003; 31: 89-96.

[38] Denny LA, Wright TC Jr. Human papillomavirus testing and screening. Best Pract Res Clin Obstet Gynaecol 2005; 19: 501-15.

[39] Castle PE, Wacholder S, Sherman ME, et al. Absolute risk of a subsequent abnormal Pap among oncogenic human papillomavirus DNA-positive cytologically negative women. Cancer 2002; 95: 2145- 51. 
[40] Koutsky L, Holmes K, Crichlow M, et al. A cohort study of the risk of cervical intraepithelial neoplasia grade 2 or 3 in relation to papillomavirus infection. N Engl J Med 1992; 327: 1272-8.

[41] Rozendal L, Walboomers JM, van der Linden JC, et al. PCR-based high-risk HPV test in cervical cancer screening gives objective risk assessment of women with cytologically normal cervical smears. Int J Cancer 1996; 68: 766- 9 .

[42] Qiao YL, Sellors JW, Eder PS, et al. A new HPV-DNA test for cervical cancer screening in developing regions: a cross-sectional study of clinical accuracy in rural China. Lancet Oncol 2008; 9: 929-36.

[43] Palefsky JM, Minkoff H, Kalish LA, et al. Cervicovaginal human papillomavirus infection in human immunodeficiency virus-1 (HIV)-positive and high risk HIV-negative women. J Natl Cancer Inst 1999; 91: 226-36.

[44] Ellerbrock TV, Chiasson MA, Bush TJ, et al. Incidence of cervical squamous intraepithelial lesions in HIV-infected women. JAMA 200; 283: 1031- 7

[45] Harris TG, Burk RD, Palesky JM, et al. Incidence of cervical squamous intraepithelial lesions associated with HIV serostatus, CD4 cell counts, and human papillomavirus test results. JAMA 2005: 293: 1471-6.

[46] Denny L, Boa R, Williamson AL, et al. Human papillomavirus infection and cervical disease in human immunodeficiency virus-1 infected women. Obstet Gynecol 2008; 111: 1380 -7.

[47] Singh D, Anastos K, Hoover D, et al. Human papillomavirus infection and cervical cytology in HIV-infected and HIVuninfected Rwandan women. J Infect Dis 2009; 199: 1851-61.

[48] Harper DM, Franco EL, Wheeler C, et al. Efficacy of a bivalent L1 virus-like particle vaccine in prevention of infection with human papillomavirus types 16 and 18 in young women: a randomized controlled trial. Lancet 2004; 364: 1757- 65.

[49] Harper DM, Franco EL, Wheeler CM, et al. Sustained efficacy up to 4,5 years of a bivalent L1 virus-like particle vaccine against human papillomavirus types 16 and 18: follow-up from a randomized control trial. Lancet 2006; 367: 1247-55.

[50] Koutsky LA, Ault KA, Wheeler CM, et al. A controlled trial of a human papillomavirus type 16 vaccine. N Engl J Med 2002; 372: 1645- 51.

[51] Mao C, Koutsky LA, Ault KA, et al. Efficacy of human papillomaviurs-16 vaccine to prevent cervical intraepithelia neoplasia: a randomized controlled trial. Obstet Gynecol 2006; 107: 18-27.

[52] Villa LL, Costa RL, Petta CA, et al. Prophylactic quadrivalent human papillomavirus (types $6,11,16$ \& 18) L1 virus-like particle vaccine in young women: a randomized double-blind placebocontrolled multicentre phase II efficacy trial. Lancet Oncol 2005; 6: 271-8.

[53] The Future II Study Group. Quadrivalent vaccine against human papillomavirus to Prevent high-grade cervical lesions. N Engl J Med 2007; 356: 1915-27.

[54] Lacey CJ. Therapy for genital human papilloma-virus related disease. J Clin Virol 2005; 32(Suppl 1): S82-90.

[55] Manhart LE, Koutsky LA. Do condoms prevent genital HPV infection, external genital warts or cervical neoplasia? A metaanalysis. Sex Trans Dis 2002; 29: 725-35.

[56] Clifford GM, Rana RK, Franceschi S, Smith JS, Gough G, Pimenta JM. Human papillomavirus genotype distribution in low-grade cervical lesions: comparison by geographic region and with cervical cancer. Cancer Epidemiol Biomarkers Prev 2005; 14 $1157-64$

(C) Lynette Denny; Licensee Bentham Open.

This is an open access article licensed under the terms of the Creative Commons Attribution Non-Commercial License (http://creativecommons.org/licenses/ by-nc/3.0/) which permits unrestricted, non-commercial use, distribution and reproduction in any medium, provided the work is properly cited. 